\title{
Cooperative Interactions of LFA-1 and Mac-1 with Intercellular Adhesion Molecule-1 in Facilitating Adherence and Transendothelial Migration of Human Neutrophils In Vitro
}

\author{
C. Wayne Smith, ${ }^{*}$ Steven D. Marlin, ${ }^{\ddagger}$ Robert Rothlein, ${ }^{\star}$ Carol Toman, ${ }^{*}$ and Donald C. Anderson $\$$ \\ * Speros P. Martel Laboratory of Leukocyte Biology, Department of Pediatrics, Baylor College of Medicine, Houston, Texas 77054; \\ ${ }^{\ddagger}$ Department of Immunology/Cell Biology, Boehringer Ingelheim Pharmaceuticals, Inc., Ridgefield, Connecticut 06877; and \\ ${ }^{\S}$ Departments of Microbiology and Immunology, and Cell Biology, Baylor College of Medicine, Houston, Texas 77054
}

\begin{abstract}
The adherence of human neutrophils to human umbilical vein endothelial cells (HUVEC) is partially dependent on the CD11/CD18 family of glycoproteins on the neutrophil and ICAM-1 on the HUVEC. The CD18 heterodimer involved in this adherence was evaluated in vitro using subunit-specific monoclonal antibodies (MAbs). The adherence of unstimulated neutrophils to IL-1-stimulated HUVEC was significantly inhibited by anti-CD11a but not CD11b MAbs, while the adherence of fMLP-stimulated neutrophils was significantly inhibited by both anti-CD11a and-CD11b. Anti-CD11a, but not anti-CD11b MAbs, reduced the adherence of unstimulated neutrophils on purified ICAM-1 to the same low level untreated neutrophils exhibited on a control protein, glycophorin. Stimulation with fMLP significantly increased neutrophil attachment to purified ICAM-1, but not to the control protein. Anti-CD11b MAbs reduced this chemotactically augmented adherence to that of unstimulated neutrophils, and in combination with anti-CD11a MAbs reduced adherence to that on the control protein. The results in this report indicate that unstimulated neutrophils exhibit LFA-1-dependent attachment to ICAM-1, and chemotactic stimulation enhances the attachment of human neutrophils to ICAM-1 by a Mac-1-dependent process.
\end{abstract}

\section{Introduction}

Adherence of human neutrophils (PMN) to monolayers of endothelial cells and to protein-coated foreign surfaces is significantly increased by stimulation with chemotactic factors and secretagogues (1-7). In each case, the CD11b/CD18 (Mac-1) heterodimer on the neutrophil's surface plays a significant role as shown by the markedly inhibitory effect of several monoclonal antibodies reactive with either CD11b or CD18 $(4,5,8,9)$. Stimulation of endothelial cells with bacterial endotoxin (LPS) $(4,10,11)$, interleukin 1 (IL-1) $(4,12,13)$, tumor necrosis factor- $\alpha(4,5,12-14)$, or lymphotoxin (13) increases the adherence of unstimulated PMN. In contrast to the rapid response following chemotactic stimulation of PMN,

Address reprint requests to Dr. Smith, Texas Children's Hospital Clinical Care Center, 8080 N. Stadium Dr., Suite 2100, Houston, TX 77054.

Received for publication 4 October 1988 and in revised form 5 January 1989.

J. Clin. Invest.

(c) The American Society for Clinical Investigation, Inc.

0021-9738/89/06/2008/10 $\$ 2.00$

Volume 83, June 1989, 2008-2017 this increase is not demonstrable until $\sim 1 \mathrm{~h}$ after stimulation, and protein synthesis is required. In addition, it appears to be only partially dependent on the CD11/CD18 family (7). The specific CD11/CD18 heterodimer of greatest importance to this cytokine-induced adherence has not been defined. We have recently obtained evidence that the CD18-dependent adherence of human PMN to cytokine-stimulated endothelial cells involves intercellular adherence molecule-1 (ICAM-1) ${ }^{1}$ on the endothelial surface (7). In light of recent evidence that ICAM-1 $(15,16)$ is a ligand for the CD11a/CD18 (LFA-1) heterodimer $(17,18)$, consideration was given to the possibility that LFA-1 plays an important role in the adherence of unstimulated PMN to cytokine-stimulated endothelial cells. Though LFA-1 seems to be uninvolved in homotypic aggregation of PMN and the adherence of PMN to foreign surfaces (8), its role in the adherence of PMN to endothelial cells has not been evaluated.

In this study, we provide evidence that LFA-1 is important to the adherence of unstimulated human PMN to human umbilical vein endothelial cells (HUVEC), that LFA-1 is most likely interacting with ICAM-1 on the endothelial cell surface, and that LFA-1 is involved in the transendothelial migration induced by activation of HUVEC with cytokines. We also provide evidence that Mac- 1 is important in the adhesion of chemotactically stimulated PMN to HUVEC, that Mac-1 on chemotactically stimulated cells may interact with ICAM-1, and that Mac-1 is involved in transendothelial migration.

\section{Methods}

Isolation of polymorphonuclear leukocytes. PMN obtained from healthy adult individuals and two patients with a severe form of $\mathrm{CD} 18$ deficiency (19) were purified from citrate anticoagulated, dextran-sedimented venous blood samples over Ficoll-Hypaque gradients and were suspended in Dulbecco's PBS (Gibco Laboratories, Grand Island, NY), pH 7.4, containing $0.2 \%$ dextrose as described (20). PMN were maintained at $4^{\circ} \mathrm{C}$ in PBS for up to $4 \mathrm{~h}$ at a concentration of $10^{7} / \mathrm{ml}$.

The response of isolated PMN to chemotactic stimulation was assessed using a modification of the shape change assay described previously (6). Cells were suspended at $10^{6} / \mathrm{ml}$ in PBS and incubated at $37^{\circ} \mathrm{C}$ for $5 \mathrm{~min}$ in the following concentrations of MLP (Sigma Chemical Co., St. Louis, MO), 0.1, 0.3, 1.0, 3.0, 10.0 nM; then cells were fixed by addition of an equal volume of $2 \%$ glutaraldehyde. Cells were scored morphologically as round, ruffled, or bipolar. The effects of MAbs was assessed by incubating the cells for $15 \mathrm{~min}$ in saturating concentration of MAb before addition of MLP.

Monoclonal antibodies. MAbs used in these studies included dilutions of ascites fluid, preparations of $\mathrm{IgG}$, and $\mathrm{F}\left(\mathrm{ab}^{\prime}\right)_{2}$ fragments. The

1. Abbreviations used in this paper: HUVEC, human umbilical vein endothelial cells; ICAM-1, intercellular adhesion molecule-1. 
anti-CD18 MAb, TS1/18 (IgG1) $(8,21)$, the anti-CD1 la MAb, TS1/22 (IgG1) $(8,21)$, and the anti-CD11b, LM2/1 (IgG1) $(22,23)$, were provided by Dr. T. Springer, Dana-Farber Cancer Institute, Boston, MA. The anti-CD1 lb MAb, OKM10 (IgG2a) (24) was obtained from Ortho Pharmaceutical Corp. (Raritan, NJ). The anti-CD11b MAb, M1/70 (25), was prepared as IgG fraction from culture supernatant using the clone obtained from American Type Culture Collection, Rockville, MD. The anti-CD1 lb MAb, 904 (IgG1) (26), was provided by Dr. R. Todd, University of Michigan, Ann Arbor, MI. An antiCD1 la MAb, R3.1 (IgG1), was developed by immunizing BALB/c mice with LFA-1 bearing lymphoblasts and screening hybridomas for inhibition of the JY and SKW3 cell aggregation induced by PMA (200 $\mathrm{ng} / \mathrm{ml}, 4 \mathrm{~h}, 37^{\circ} \mathrm{C}$ ) (15). R6.5.D6 (IgG2a) was developed by fusing spleen cells from mice immunized with a battery of ICAM-1 bearing cell lines. Its profile of reactivity in lymphoblast aggregation assays and the molecular weight of its immunoprecipitated antigen on JY cells are identical to RR1/1 anti-ICAM-1 $(7,15,16)$. The anti-HLA framework MAb was W6/32 (IgG2a) $(8,27)$. Two antineutrophil MAbs, 5G4 (IgG1) and 4A5 (IgG1), were prepared by immunizing BALB/c mice with membrane preparations from PMN obtained from patients with leukocyte adhesion deficiency. Each exhibited approximately the same degree of binding to unstimulated PMN as the anti-CD1 $1 \mathrm{~b}$ MAbs, and 4A5 was used as a "binding control" in the adherence and migration assays. These antibodies have been evaluated in our laboratory for their ability to inhibit neutrophil adherence to endothelial cells, and they were found to be without effect. All MAbs that bind to PMN were titered using flow cytometry (FACScan; Becton Dickinson, Mountain View, CA) to determine the concentration that saturated surface binding sites of stimulated cells (i.e., stimulation with $10 \mathrm{nM} \mathrm{fMLP}, 37^{\circ} \mathrm{C}$, $15 \mathrm{~min}$ ). In most functional studies, MAbs were initially used at twice the saturating concentration.

Immunofluorescence flow cytometry. Indirect immunofluorescent staining of mouse-human hybrids expressing $\alpha \mathrm{L}$ (CD1 1a) or $\beta$ (CD18) subunits of human LFA-1 were done by treating the cells with hybridoma culture supernates specific for human $\alpha \mathrm{L}$ or $\beta$, or control supernate X63 as previously described (28). Stained cells were analyzed on an Epics $\mathrm{V}$ flow cytometer gated by forward angle scatter to exclude dead cells. Data from the analysis of $10^{4}$ cells are expressed as fluorescence intensity on a logarithmic scale.

Preparation of human umbilical vein endothelial cells. HUVEC were harvested $(29,30)$ and characterized as to acLDL binding (31) and Factor VIII expression (29) according to established techniques. Cells from 5-10 umbilical cords were pooled and plated in RPMI 1640 containing $10 \% \mathrm{FCS}$, antibiotics, heparin $(0.1 \mathrm{mg} / \mathrm{ml})$, and endothelial cell growth factor $(0.05 \mathrm{mg} / \mathrm{ml})$, and maintained for $3-4 \mathrm{~d}$ at $37^{\circ} \mathrm{C}, 5 \%$ $\mathrm{CO}_{2}$ humidified atmosphere. Visually confluent monolayers on gelatin $(0.1 \%)$ and fibronectin $\left(5 \mu \mathrm{g} / \mathrm{cm}^{2}\right)$-coated 25 -mm round glass coverslips were prepared from first passage cells harvested with $0.05 \%$ trypsin and $0.02 \%$ EDTA in PBS. Monolayers in fibronectin $\left(5 \mu \mathrm{g} / \mathrm{cm}^{2}\right)$ coated 96-well microtiter plates were prepared from first and second passage cells and grown to confluence (1-3 d). HUVEC were pretreated with various concentrations of LPS (Sigma, Escherichia coli 026:B6), or IL-1 (Genzyme, cell derived) in most instances for $4 \mathrm{~h}$, a time previously shown to be optimal for the enhancement of neutrophil adherence (7).

Adherence assay. A visual adherence assay was utilized as previously described (6) with the exception that adherence to HUVEC monolayers was assessed instead of adherence to protein-coated glass. HUVEC monolayers on 25-mm round glass coverslips were washed by dipping three times in two changes of PBS and immediately inserted into the adherence chambers specifically made for use with an inverted microscope and phase-contrast optics. The chambers consisted of two metal plates designed to hold two $25-\mathrm{mm}$ round cover glasses separated by a Sykes-Moore chamber O-ring (Bellco Glass, Inc., Vineland, $\mathrm{NJ}$ ). Within this closed compartment PMN could be observed as they contacted the HUVEC monolayer. PMN suspended in PBS ( $10^{6}$ cells/ $\mathrm{ml})$ or pretreated with low concentrations of $\operatorname{PMLP}(2,3,6,32-34)$ were injected into the chamber and allowed to settle onto the mono- layer for a period of $500 \mathrm{~s}$. The number of PMN in contact with the monolayer was determined by counting at least 10 microscopic fields ( $50 \times$ objective), and the chamber inverted for an additional $500 \mathrm{~s}$. The percentage of cells remaining in contact with the monolayer was determined and is expressed in Results as percent adherence. In blocking experiments, HUVEC were pretreated with MAbs for $20 \mathrm{~min}$ then washed three times by dipping in two changes of PBS before evaluating adherence. PMN were pretreated for $5 \mathrm{~min}$; then the cell suspension was injected into the adherence chamber in most instances without washing. It should be noted that the procedure used in this study does not utilize shear stress $(35,36)$ as with techniques requiring a washing step (4, 5, 9, 37-39). Adherence of PMN to protein-coated glass was performed as previously described (6) with the exception that the glass coverslip was incubated with a $5 \%$ solution of human serum albumin (HSA) in PBS for $45 \mathrm{~min}$ at $37^{\circ} \mathrm{C}$, then rinsed in PBS before being inserted into the adherence chamber. PMN were exposed to PMLP (10 $\mathrm{nM}, 5 \mathrm{~min}$ ) before injection into the adherence chamber.

The percentage of cells migrating through the endothelial monolayer was also determined using previously described criteria $(7,28,40$, 41). Under phase contrast optics, PMN adherent to endothelium are round and appear refractile with a surrounding halo. In contrast, the leukocytes become remarkably flattened after migrating to a position between the monolayer and the substratum, they lose the refractile appearance, and intracellular granules are readily seen. The focal plane for these leukocytes is beneath the nuclei of the endothelial cells and that for the PMN adherent to the upper surface of the monolayer is unequivocally above.

Homotypic aggregation of PMN was performed as previously described (8) using phorbol myristate acetate (PMA; Sigma Chemical Co.) at $100 \mathrm{nM}$ as the aggregating stimulus. Inhibition induced by monoclonal antibodies was calculated from determinations of area under the curve.

Preparation of monolayers of purified ICAM-1. ICAM-1 was purified from detergent lysates of SK-Hep-2 cells by immunoaffinity chromatography essentially as previously described (17) with the exception that anti-ICAM-1 MAb R6.5.D6 was used in place of MAb RR1/1. In addition, the pH 11.0 buffer wash was omitted. Artificial lipid vesicles containing ICAM-1 or control protein glycophorin (Sigma Chemical Co.) were prepared as previously described (17). Glass coverslips (previously washed in $7 \times$ detergent, rinsed in distilled water, treated with $0.5 \mathrm{~N} \mathrm{NaOH}$ for $4 \mathrm{~h}$, and rinsed in distilled water) were prepared by placing $20 \mu \mathrm{l}$ of vesicle suspension in the center of a $25-\mathrm{mm}$ round coverslip and incubating at $37^{\circ} \mathrm{C}$ for $45 \mathrm{~min}$. In addition, ICAM-1 was also prepared by eluting from the R6.5.D6 column in the detergent octylglucoside and diluted to $0.25 \%$, a point below the critical micelle concentration of the detergent. Coverslips were prepared with this material by spotting a 20- $\mu$ l aliquot of the ICAM- 1 solution and then incubating for $45 \mathrm{~min}$ at $37^{\circ} \mathrm{C}$, followed by incubation of the coverslip in $5 \% \mathrm{HSA}$ for $45 \mathrm{~min}$ at $37^{\circ} \mathrm{C}$. The coverslips spotted with lipid vesicles containing ICAM-1 or directly coated with ICAM-1 were washed in PBS, mounted in adherence chambers, and adherence of PMN was performed as described above. The presence of ICAM-1 on the coverslip was confirmed using immunofluorescence. Coverslips were incubated for $30 \mathrm{~min}$ with R6.5.D6 $(10 \mu \mathrm{g} / \mathrm{ml})$, washed in PBS, and then incubated with FITC-labeled goat anti-mouse IgG antiserum. Coverslips were then washed in PBS, mounted in glycerol containing phenylene diamine $(1 \mathrm{mg} / \mathrm{ml})$, and photographed under epi-illumination (Leitz Diaplan microscope; E. Leitz, Inc., Rockleigh, NJ).

Data presentation. Results are presented as means $\pm 1 \mathrm{SD}$, and $n$ $=$ the number of separate experiments. Statistical assessments were made using analysis of variance and Dunnett's $t$ test, or Student's $t$ test.

\section{Results}

CD1 Ia and ICAM-1 in the attachment of neutrophils to HUVEC. TS1/22 and R3.1, two anti-CD11a MAbs, were used in these studies. R3.1, a newly developed MAb was shown to 


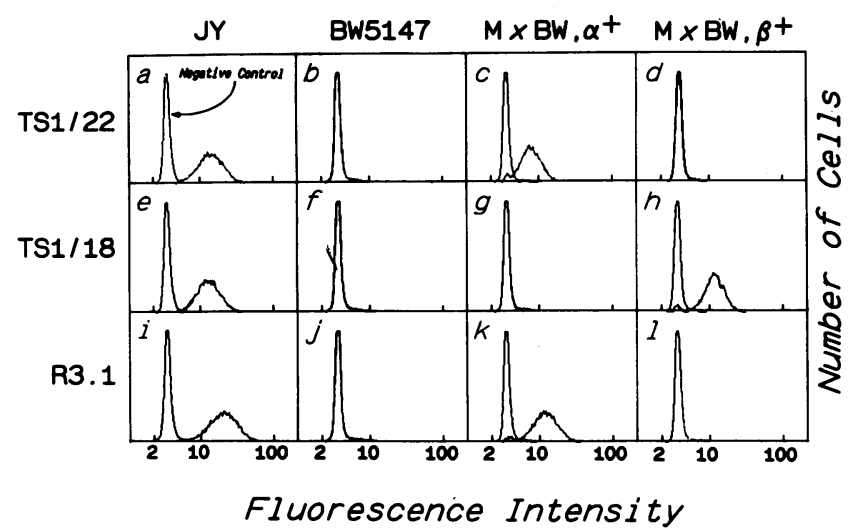

Figure 1. Specificity of monoclonal antibody R3.1 as determined by immunofluorescence flow cytometry. Human JY cells, mouse BW5147 cells, and mouse-human hybrids expressing either the human LFA-1 $\alpha(\mathbf{M} \times \mathbf{B W}, \alpha+)$ or $\beta(\mathbf{M} \times \mathbf{B W}, \beta+)$ subunits were stained with negative control MAb $\times 63$, positive control MAb TS1/22 and TS1/18 (specific for $\alpha \mathrm{L}$ and $\beta$, respectively), and MAb R3.1.

recognize CD1 1a by the fact that it bound to hybridomas (42) expressing mouse/human hybrid LFA-1 heterodimers only if the expressed heterodimer was human CD11a/mouse CD18 (Fig. 1). R3.1 failed to bind to mouse CD11a/human CD18 heterodimers. R3.1 did not bind to CD18-deficient PMN, did not show increased binding to normal PMN after chemotactic stimulation, exhibited prominent binding to lymphocytes, and failed to inhibit homotypic aggregation of PMN induced by PMA.

Both anti-CD11a MAbs significantly reduced the attachment of PMN to HUVEC stimulated with either $0.3 \mathrm{U} / \mathrm{mi}$ $\mathrm{IL}-1$, or $10 \mathrm{ng} / \mathrm{ml} \mathrm{LPS}$ as shown by the following data. The level of adherence of unstimulated PMN to unstimulated HUVEC was $16.9 \pm 3.7 \%(n=23)$. Exposure of the HUVEC to IL-1 or LPS for $4 \mathrm{~h}$ increased adherence to $91.3 \pm 7.3 \%(n=19)$ and $75.4 \pm 5.2 \%(n=21)$, respectively. $R 3.1$ was maximally active in reducing adherence at $4 \mu \mathrm{g} / \mathrm{ml}$ when added to the PMN suspension 5 min before injection of the cells into the adherence chamber. The magnitude of the effect was $<50 \%$ inhibition in most experiments. Similar results were obtained with $5 \mu \mathrm{g} / \mathrm{ml} \mathrm{TS1/22}$. One anti-ICAM-1 MAb, R6.5.D6, was used in these studies and found to produce the same degree of inhibition as the anti-CD1 la MAbs when preincubated at 4 $\mu \mathrm{g} / \mathrm{ml}$ with the HUVEC monolayer for $20 \mathrm{~min}$ at $37^{\circ} \mathrm{C}$. A mixture of R6.5.D6 and R3.1 did not inhibit adherence any more than either antibody when used alone. Furthermore, the level of adherence of PMN from two patients deficient in CD11/CD18 was not significantly different from PMN treated with R3.1 or PMN on HUVEC pretreated with R6.5.D6 (Fig. 2). Control MAb, 4A5 of the same isotype as R3.1 did not significantly reduce adhesion (Fig. 2).

$C D 11 b$ in the attachment of neutrophils to HUVEC. Studies from other laboratories have shown that anti-CD11b monoclonal antibodies reduce the attachment of PMN stimulated with either chemotactic factors or secretagogues to unstimulated HUVEC $(4,9,43)$. We attempted to determine the role played by CD1 $1 \mathrm{~b}$ in the attachment of unstimulated PMN to HUVEC stimulated with either IL-1 or LPS. The four monoclonal antibodies reactive with $\mathrm{CD} 1 \mathrm{lb}$ were used in the adherence assay with HUVEC (Fig. 3) at twice the concentra-

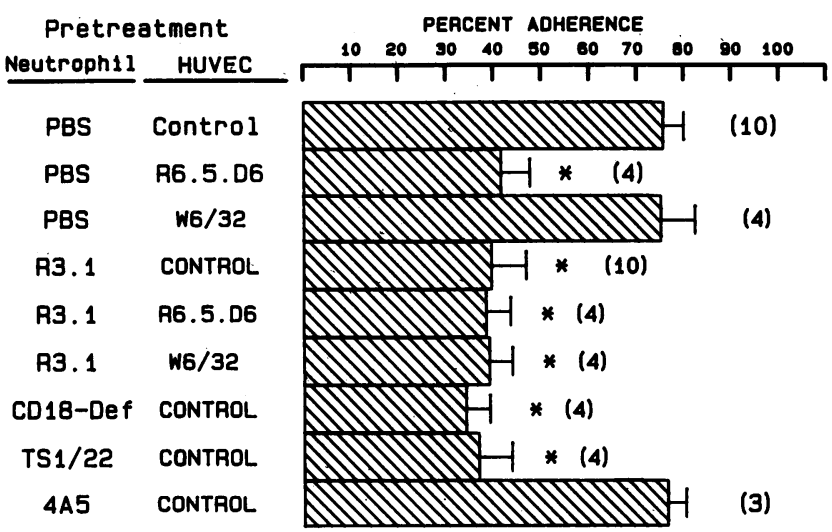

Figure 2. Adherence of human PMN to LPS stimulated HUVEC. HUVEC monolayers on gelatin-coated glass coverslips were exposed to LPS $(10 \mathrm{ng} / \mathrm{ml})$ for $4 \mathrm{~h}$, washed by dipping in PBS and incubated $15 \mathrm{~min}$ at $37^{\circ} \mathrm{C}$ with either PBS (Control), $10 \mu \mathrm{g} / \mathrm{ml} \mathrm{R6.5.D6} \mathrm{IgG} \mathrm{or}$ $10 \mu \mathrm{g} / \mathrm{ml} \mathrm{W6/32} \mathrm{IgG.} \mathrm{The} \mathrm{monolayers} \mathrm{were} \mathrm{washed} \mathrm{by} \mathrm{dipping} \mathrm{in}$ PBS and placed in adherence chambers. PMN from adult normal donors were incubated for $15 \mathrm{~min}$ at room temperature in PBS, 5 $\mu \mathrm{g} / \mathrm{ml} \mathrm{R3.1} \mathrm{IgG,} 5 \mu \mathrm{g} / \mathrm{ml} \mathrm{TS} 1 / 22 \mathrm{IgG}$, or $10 \mu \mathrm{g} / \mathrm{ml} \mathrm{4A5}$, and the cell suspension containing antibody was injected in the adherence chamber. PMN from two patients genetically deficient in $\mathrm{CD} 18$ were incubated for $15 \mathrm{~min}$ at room temperature before being injected into the adherence chamber. Adherence was determined using a visual assay at room temperature. ( ), number of separate experiments. ${ }^{*} P$ $<0.01$ compared to control without added MAb.

tions shown by flow cytometry to saturate the binding sites on PMN. The anti-CD1 1b MAbs produced no significant inhibition of adherence. Thus, MAbs of the same isotype but different antigen specificities (e.g., R3.1, IgG1, anti-CD11a; and

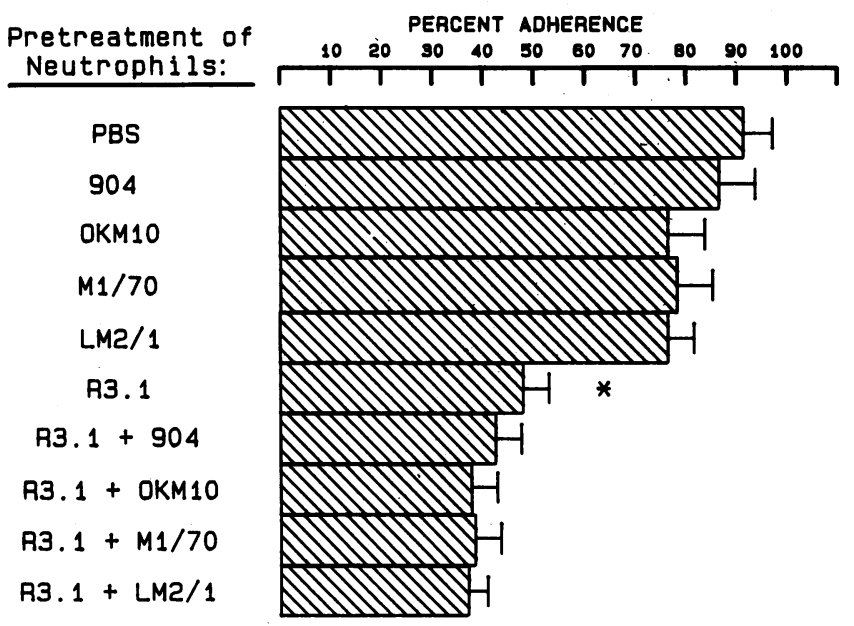

Figure 3. Adherence of human PMN to HUVEC stimulated for $4 \mathrm{~h}$ with IL-1. HUVEC monolayers on gelatin-coated glass coverslips were exposed to IL-1 $(0.3 \mathrm{U} / \mathrm{ml})$ for $4 \mathrm{~h}$, washed by dipping in PBS and placed in adherence chambers. PMN from adult normal donors were incubated for $15 \mathrm{~min}$ at room temperature in PBS or the monoclonal antibodies indicated at a concentration of $5 \mu \mathrm{g} / \mathrm{ml} \mathrm{IgG}$ for each antibody. This concentration was chosen because it saturates all binding sites as shown by flow cytometry. The cell suspension containing the antibody was then injected into the adherence chamber, and adherence determined using a visual assay at room temperature. ${ }^{*} P<0.01$ compared to PBS control. Combinations of R3.1 with other antibodies did not reduce adherence below that with R3.1. $n=5$ 


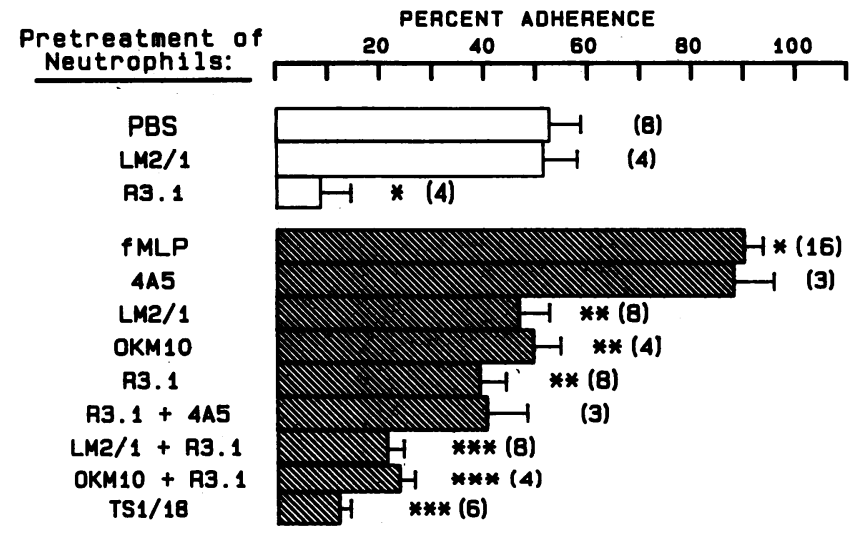

Figure 4. Effect of chemotactic stimulation on the adherence of human PMN to HUVEC stimulated for $18 \mathrm{~h}$ with IL-1. HUVEC monolayers on gelatin-coated glass coverslips were exposed to IL-1 $(0.3 \mathrm{U} / \mathrm{ml})$ for $18 \mathrm{~h}$, washed by dipping in PBS and placed in adherence chambers. PMN from normal adult donors were incubated for 5 min at room temperature in PBS (open bars) with and without the monoclonal antibodies indicated, or in PBS with $10 \mathrm{nM}$ fMLP (hatched bars) with and without the monoclonal antibodies indicated. A concentration of $5 \mu \mathrm{g} / \mathrm{ml}$ IgG was used for each antibody since this concentration is in excess of that needed to saturate surface binding sites as shown by flow cytometry. These cell suspensions were then injected into the adherence chamber, and adherence determined using a visual assay at room temperature. ( ), number of separate experiments. ${ }^{*} P<0.01$ compared to $\mathrm{PBS}$ alone; ${ }^{* *} P<0.01$ compared to fMLP stimulation alone; ${ }^{* * *} P<0.01$ compared to fMLP with R3.1 alone.

LM2/1, IgG1, anti-CD11b) produced opposite effects on the adherence of unstimulated human PMN to cytokinestimulated HUVEC monolayers (R3.1 inhibited and LM2/1 did not).

Each of the anti-CD1 1b MAbs was evaluated for the ability to inhibit homotypic aggregation induced by stimulation of PMN with PMA. OKM10, 904, LM2/1 and M1/70 were maximally active (producing $>75 \%$ inhibition) at concentrations of $5 \mu \mathrm{g} / \mathrm{ml} \mathrm{IgG}$. In contrast, R3.1 and TS1/22 were inactive as inhibitors of homotypic aggregation (data not shown). In addition, each of the anti-Mac- 1 MAbs at $5 \mu \mathrm{g} / \mathrm{ml}$ inhibited the $\mathrm{AMLP}$-enhanced adherence to HSA-coated glass by greater than $83 \%(n=4, P<0.001)$ while $\mathrm{R} 3.1$ and TS1 $/ 22$ at $5 \mu \mathrm{g} / \mathrm{ml}$ produced no significant effect $(n=6)$.

To evaluate the possible interaction of the CD18 heterodimers with ICAM-1 on the endothelial cells, the endothelial monolayers were stimulated for $18 \mathrm{~h}$ with IL-1 $(0.3 \mathrm{U} / \mathrm{ml})$. At this time ICAM-1 expression remains high (12) and the ICAM-1-independent adhesion mechanisms perhaps mediated by molecules such as ELAM-1 have returned to levels in unstimulated cells $(12,44)$. As shown in Fig. 4, adherence of unstimulated PMN to these monolayers is significantly inhibited by R3.1, but not by LM2/1. R3.1 reduced adherence to $9.2 \pm 3.2 \%$, a value comparable to $8.3 \pm 2.5 \%(n=4)$ with TS1/18 pretreatment of the PMN and $10.1 \pm 2.8 \%(n=4)$ after pretreatment of the monolayer with R6.5.D6. Chemotactic stimulation of the PMN (fMLP, $10 \mathrm{nM}$ ) immediately before assaying adherence caused a significant increase in adherence. In contrast to the results with unstimulated PMN, this chemotactically augmented adherence was inhibited by monoclonal antibodies reactive with Mac-1 (LM2/1 and OKM10) as well as R3.1. Furthermore, when R3.1 was combined with antiMac-1 antibodies in the same experiment, the inhibition was significantly greater than with either antibody alone. In paired experiments, R6.5.D6 $(5 \mu \mathrm{g} / \mathrm{ml})$ incubated with the endothelium resulted in a level of adherence of fMLP-stimulated PMN to 18-h IL-1-stimulated HUVEC $(25.2 \pm 2.5, n=4)$ not statistically different from the level of adherence when the stimulated PMN were incubated with a combination of LM $2 / 1$ and R3.1 each at $5 \mu \mathrm{g} / \mathrm{ml}(22.5 \pm 3.5, n=4)$.

$C D 11 a$ and CD11b in the attachment of neutrophils to purified ICAM-1. The purity of the ICAM-1 preparation is shown in Fig. 5, and the presence of ICAM- 1 on the coverglass surface after incubation with the ICAM-1-containing lipid vesicle preparation was demonstrated by the binding of MAb R6.5.D6 (Fig. 6). As can be seen, the limit of the spot of ICAM-1 was sharply demarcated. R6.5.D6 failed to bind to the coverglass surface following incubation with glycophorin containing vesicle preparations. PMN adhered very poorly to glycophorin vesicles or glycophorin adsorbed to the glass surface, and the few attached cells appeared spherical. In contrast, greater than $65 \%$ of the PMN adhered to membranes containing ICAM-1 (Fig. 6) or to ICAM-1 adsorbed to a glass surface, and these cells were ruffled and occasionally bipolar in appearance (Fig. 7). This was in distinction to the markedly flattened appearance of PMN on untreated glass (Fig. 7).

The anti-CD1 1a, anti-CD11b, and anti-ICAM-1 monoclonal antibodies were evaluated for the ability to inhibit attachment of PMN to ICAM-1 (Fig. 6 and 8). None of the antiCD1 lb antibodies were inhibitory in this setting. Anti-CD11a antibodies produced significant inhibition at concentrations sufficient to saturate binding sites on the PMN $(4 \mu \mathrm{g} / \mathrm{ml}$ for R3.1; and $5 \mu \mathrm{g} / \mathrm{ml}$ for TS1/22). R6.5.D6 $(10 \mu \mathrm{g} / \mathrm{ml} \mathrm{IgG}$ $\left.F\left(a b^{\prime}\right)_{2}\right)$ inhibited adherence to the same degree as R3.1, and the combination of the two in the same experiment produced no further inhibition. W6/32 $\left(20 \mu \mathrm{g} / \mathrm{ml} \operatorname{IgG} F\left(a^{\prime}\right)_{2}\right)$, a nonbinding control, was without effect. Neither R6.5.D6 (Fig. 4) nor W6/32 inhibited the adherence of PMN to untreated glass.

Chemotactic stimulation of PMN resulted in enhanced adherence to endothelial monolayers stimulated for $18 \mathrm{~h}$ with IL-1. To evaluate the possibility that this was augmented adherence to ICAM-1, the effects of AMLP stimulation on adherence of PMN to purified ICAM-1 or glycophorin was assessed. Chemotactic stimulation (fMLP, $10 \mathrm{nM}$ ) did not increase adherence to glycophorin (unstimulated, $7 \pm 4 \mathrm{PMN} / 5$ fields; fMLP, $8 \pm 5$ PMN/ 5 fields, $n=6$ ) As seen in Fig. 9, chemotac-

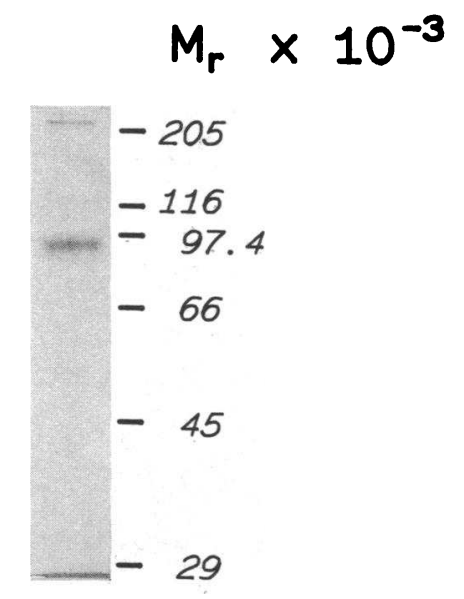

Figure 5. SDS-PAGE of purified ICAM-1. Approximately $250 \mathrm{ng}$ of ICAM-1 purified from SK-Hep-2 cells by immunoaffinity chromatography was electrophoresed under nonreducing conditions on a SDS-9\% polyacrylamide gel. Protein was then visualized by silver staining. 

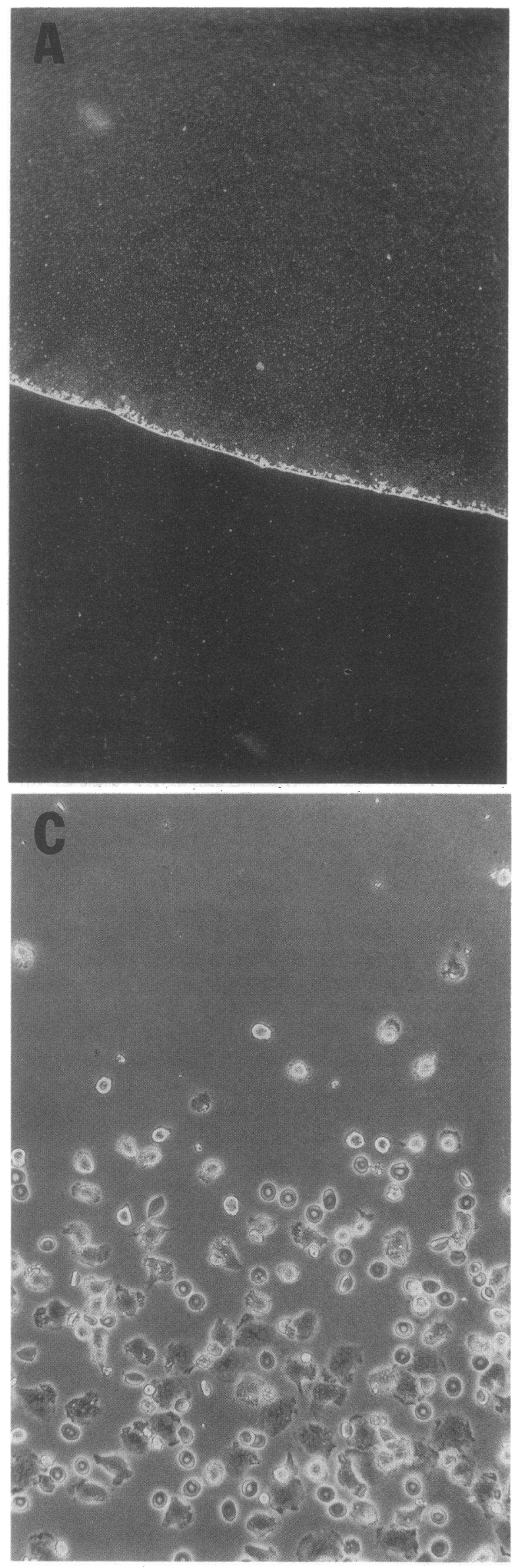

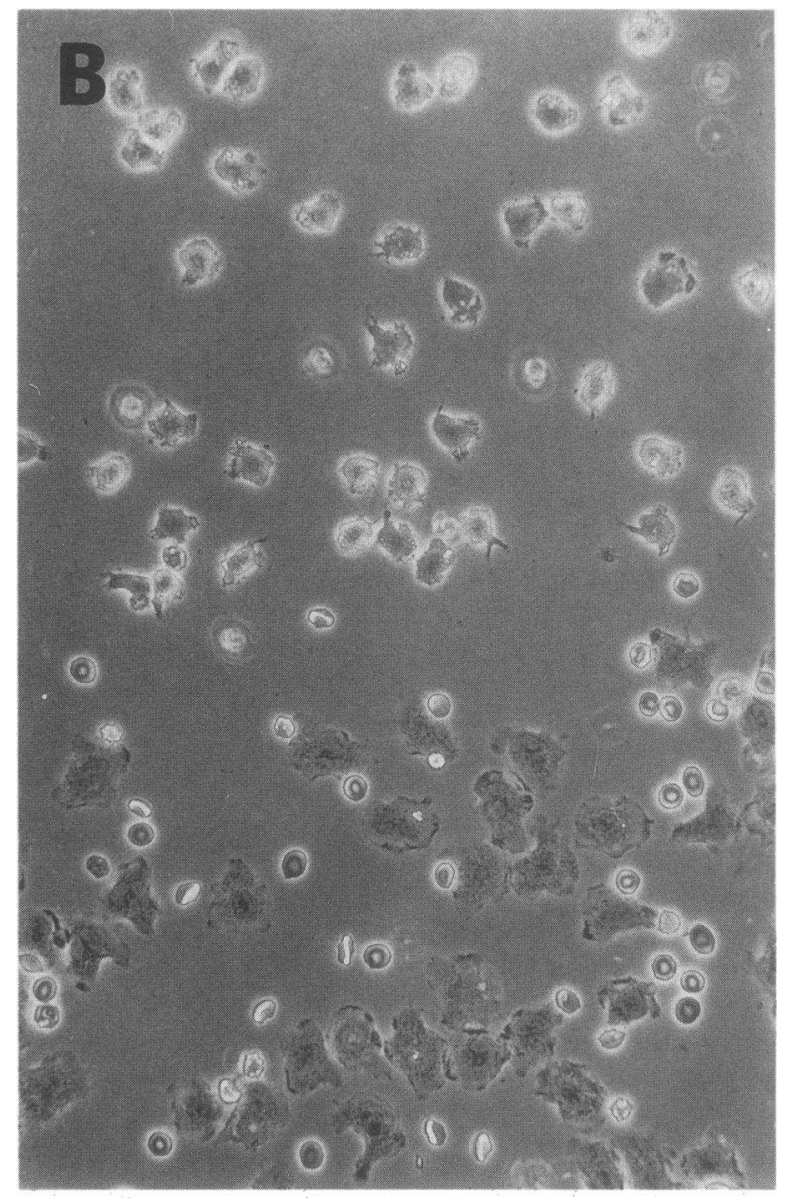

Figure 6. Adherence of human PMN to purified ICAM-1. (A) Immuno-fluorescent demonstration of binding of R6.5.D6 to ICAM-1. A 20- $\mu$ l spot of ICAM-1 containing lipid vesicle preparation was incubated on a $25 \mathrm{~mm}$ diam glass coverslip for $45 \mathrm{~min}$ at $37^{\circ} \mathrm{C}$, washed in PBS, and exposed to R6.5.D6 $(10 \mu \mathrm{g} / \mathrm{ml} \mathrm{IgG})$ for $30 \mathrm{~min}$. After washing, the coverglass was incubated with 1:100 dilution of FITC-labeled goat antimouse antiserum for $30 \mathrm{~min}$, washed, and photographed. The limit of the spot produced by the ICAM-1-containing vesicle preparation is clearly shown. $(B)$ Phase-contrast microscopic image of adherent PMN at the edge of an ICAM-1-containing vesicle spot. The coverglass with the ICAM-1 was inserted into an adherence chamber. PMN suspended in PBS were injected, and allowed to contact the surface for $500 \mathrm{~s}$ before the chamber was inverted. After an additional $500 \mathrm{~s}$ the attached cells were photographed. In the lower half of the photograph, the PMN are on untreated glass, and in the upper half they are on the membrane. $(C)$ Phase-contrast microscopic image of adherent PMN at the edge of

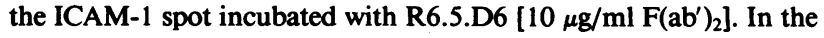
lower half of the photograph, the PMN are on untreated glass, and in the upper half, on the membrane. 

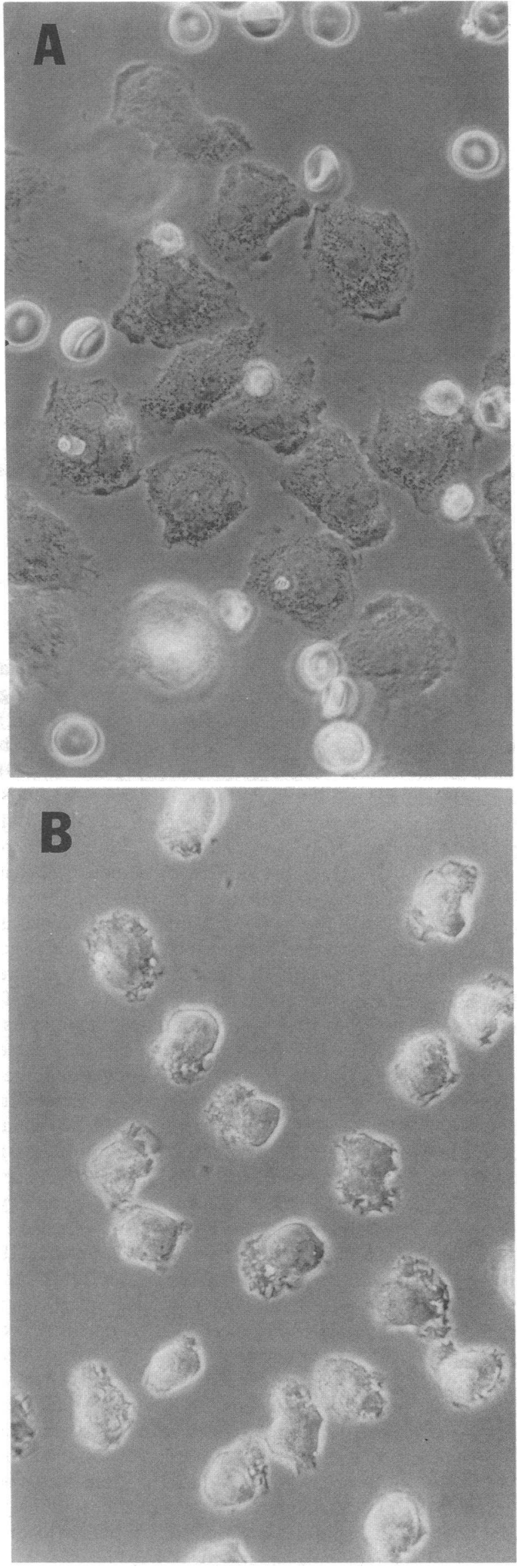

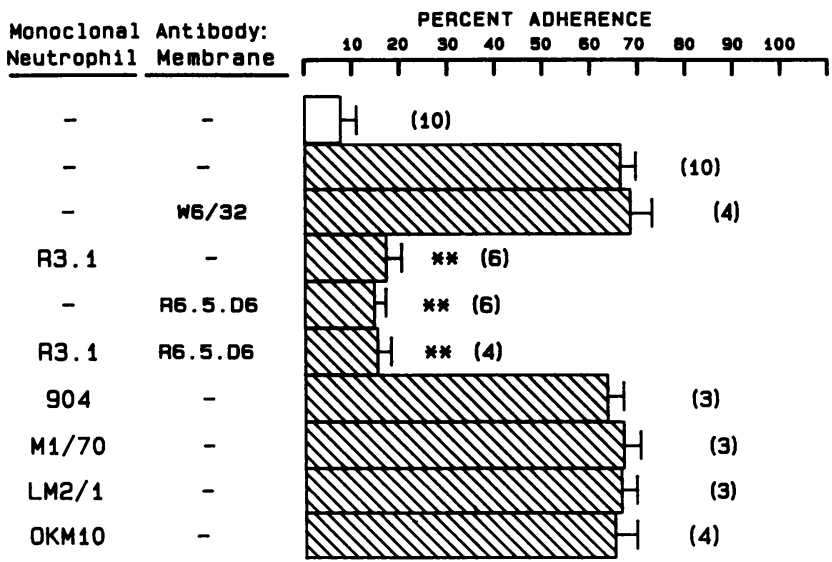

Figure 8. Effects of monoclonal antibodies on the adherence of human PMN to purified ICAM-1. Coverglasses spotted with vesicles containing either glycophorin (open bar) or ICAM-1 (hatched bars) were inserted into adherence chambers. The fluid in the adherence chamber was exchanged with PBS or PBS containing W6/32 (20 $\left.\mu \mathrm{g} / \mathrm{ml} \mathrm{F}\left(\mathrm{ab}^{\prime}\right)_{2}\right)$ or R6.5.D6 $\left(10 \mu \mathrm{g} / \mathrm{ml} \mathrm{F}\left(\mathrm{ab}^{\prime}\right)_{2}\right)$. The chamber fluid was exchanged after $15 \mathrm{~min}$ incubation at room temperature with a PMN suspension in PBS alone or PBS containing the indicated monoclonal antibody (5 $\mu \mathrm{g} / \mathrm{ml} \mathrm{IgG)}$. Adherence was determined using a visual assay at room temperature. ( ), number of separate experiments, ${ }^{* *} P<0.001$ compared to adherence to ICAM-1 without added MAb.

tic stimulation resulted in significant enhancement of attachment to ICAM-1. In contrast to the adherence of unstimulated PMN to purified ICAM-1, monoclonal antibodies reactive with CD11b (LM2/1 and OKM10) produced significant inhibition, bringing the level of attachment down to prestimulation levels. R3.1 also reduced attachment, and the combination of R3.1 with either LM2/1 or OKM10 produced what appeared to be additive effects. This combination produced the same degree of inhibition as did monoclonal antibodies reactive with CD18 (TS1/18) and ICAM-1 (R6.5.D6) individually. Note that an isotype-matched binding control, 4A5, did not inhibit adherence either alone or in combination with either LM2/1 or R3.1 (Fig. 9).

Effects of fMLP stimulation on CD18-independent adhesion to endothelium. To determine if chemotactic stimulation activates adherence mechanisms other than those associated with the CD11/CD18 family of glycoproteins, we evaluated the effects of AMLP stimulation on the adherence of CD18-deficient PMN. Exposure of CD18-deficient PMN to AMLP (10 $\mathrm{nM}$ ) for $5 \mathrm{~min}$ did not increase adherence to unstimulated endothelial monolayers (adherence without fMLP, $5.4 \pm 1.2 \%$; with fMLP, $3.4 \pm 0.7 \%, n=4$ ). Adherence was not increased to $18 \mathrm{~h} \mathrm{IL}-1$ stimulated endothelial monolayers (without fMLP, $10.4 \%$; with fMLP, $8.9 \%, n=2$ ), or to purified ICAM-1 adsorbed to glass (without fMLP, $2.8 \pm 2.0 \%$; with fMLP, $2.5 \pm 2.4 \%, n=4$ ). Stimulation of HUVEC monolayers with IL-1 for $4 \mathrm{~h}$ significantly increases attachment of CD18-deficient PMN (7). As with the other experiments, chemotactic stimulation failed to augment the neutrophil's attachment to HUVEC stimulated for $4 \mathrm{~h}$ with IL-1.

Figure 7. Adherence of human PMN to untreated glass $(A)$ and to purified ICAM-1 (B). 


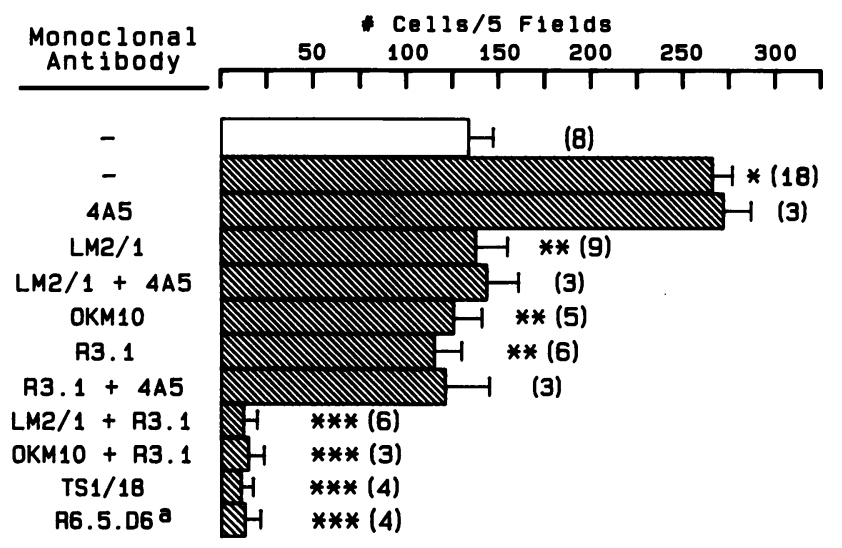

Figure 9. Effects of chemotactic stimulation on the adherence of PMN to purified ICAM-1. Coverglasses spotted with vesicles containing ICAM- 1 were inserted into adherence chambers. The fluid in the adherence chamber was exchanged with PBS, or (a) PBS containing R6.5.D6 $\left(10 \mu \mathrm{g} / \mathrm{ml} \mathrm{F}\left(\mathrm{ab}^{\prime}\right)_{2}\right)$. After $15 \mathrm{~min}$ incubation at room temperature the chamber fluid was exchanged with PMN suspended in PBS alone (open bars) or PBS containing $10 \mathrm{nM}$ fMLP (hatched bars) with or without monoclonal antibodies $(5 \mu \mathrm{g} / \mathrm{ml} \mathrm{IgG})$ as indicated. Adherence was determined using a visual assay at room temperature. ( ), number of separate experiments; ${ }^{*} P<0.01$ when compared to PBS alone; ${ }^{* *} P<0.01$ when compared to fMLP without monoclonal antibodies; ${ }^{* * *} P<0.01$ when compared to values when PMN were exposed to both fMLP and R3.1.

$C D 11 a$ and $C D 11 b$ in the transendothelial migration of human neutrophils. Migration of unstimulated PMN through monolayers of unstimulated HUVEC on gelatin-coated glass is rarely seen during the 1,000-s observation period used in these studies (7). However, when the HUVEC monolayer has been exposed to IL-1 $(0.3 \mathrm{U} / \mathrm{ml})$ for $3-4 \mathrm{~h}$ before the application of unstimulated PMN, $>70 \%$ of the PMN become activated upon contact with the monolayer as evidenced by their ruffled and bipolar morphology (7). These cells migrate through the endothelium to a position between the monolayer and the substratum, and appear flattened under phase-contrast microscopy, though they still retain the motile, bipolar configuration. We have previously shown that anti-CD18 and antiICAM-1 monoclonal antibodies markedly inhibit this migration, and that CD18-deficient PMN fail to migrate (7). To extend this work, we utilized the anti-CD1 $1 \mathrm{a}$ and anti-CD11b monoclonal antibodies (Fig. 10). The three anti-CD1 lb MAbs and the binding control MAb, 4A5, failed to significantly inhibit migration. In contrast, both anti-CD1 1 a MAbs markedly inhibited migration. Of particular interest was the finding that when used in combination with R3.1, anti-CD11b MAbs 904, OKM10, and LM2/1 profoundly reduced migration to levels significantly less than with R3.1 alone. The binding control MAb was not inhibitory alone and did not augment the inhibitory effects of R3.1. In separate experiments, none of the MAbs induced shape change or inhibited the shape change induced by concentrations of fMLP ranging from 0.1 to $10.0 \mathrm{nM}$.

\section{Discussion}

The results in this report demonstrate that unstimulated PMN specifically adhere to purified ICAM-1 either in an artificial membrane or adsorbed to a glass surface, and that this adher-

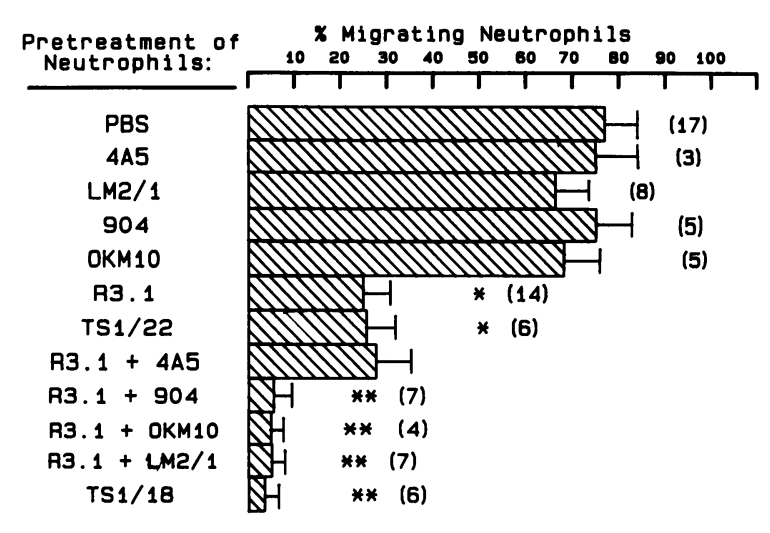

Figure 10. Transendothelial migration of human PMN and effects of monoclonal antibodies. HUVEC monolayers on gelatin-coated glass were incubated with IL-1 $(0.5 \mathrm{U} / \mathrm{ml})$ for $4 \mathrm{~h}$, washed by dipping in PBS and inserted into adherence chambers. PMN were incubated for 15 min at room temperature in either PBS or PBS containing the indicated monoclonal antibody $(5 \mu \mathrm{g} / \mathrm{ml} \mathrm{IgG})$. This cell suspension was injected into the adherence chamber, and transendothelial migration was determined after incubation at $37^{\circ} \mathrm{C}$ for $1,000 \mathrm{~s}$ using a visual assay. ( ), number of separate experiments; ${ }^{*} P<0.01$ when compared with the PBS control; ${ }^{* *} P<0.01$ when compared with the level of adherence in the presence of R3.1.

ence requires LFA-1 on the surface of the neutrophil. The data supporting this conclusion come from experiments showing that anti-CD11a monoclonal antibodies (R3.1 and TS1/22) completely inhibit adherence to ICAM-1 while anti-CD11b monoclonal antibodies (OKM10, 904, LM2/1, and M1/70) fail to show significant inhibition, that CD18-deficient PMN do not adhere to purified ICAM-1, and an anti-ICAM-1 monoclonal antibody (R6.5.D6) completely inhibits adherence to purified ICAM-1. Our studies clearly demonstrate that attachment of unstimulated PMN to endothelial cells also involves ICAM-1-LFA-1 interactions. Supporting evidence is found in the effects of monoclonal antibodies on adhesion to HUVEC monolayers in vitro: (a) Unstimulated PMN adhere to HUVEC monolayers stimulated for $18 \mathrm{~h}$ with IL-1 in significantly greater numbers than to unstimulated monolayers. ICAM-1 is implicated in this attachment since under these experimental conditions, the ICAM-1-independent endothelial adhesive factors such as ELAM-1 have been reported to have returned to the level of unstimulated cells $(12,44)$ while ICAM-1 expression remains high $(7,12)$, and the anti-ICAM-1 MAb, R6.5.D6, produces $>85 \%$ inhibition of adherence. LFA-1 is implicated since CD18-deficient PMN adhere very poorly to these monolayers, and the anti-CD11a MAb, R3.1, produces $83.4 \%$ inhibition of adherence while an anti-CD11b MAb (LM2/1) is without effect. (b) Unstimulated PMN adhere to HUVEC monolayers stimulated for 3-4 $\mathrm{h}$ with IL-1 or LPS in significantly greater numbers than to unstimulated monolayers. ICAM-1 is implicated in this adherence since ICAM-1 expression is high at this time $(7,12)$, and the antiICAM-1 MAb produces significant inhibition of adherence (7). LFA-1 is implicated since the adherence of CD18-deficient PMN is significantly less than that of normal PMN, the antiCD1 la MAbs, R3.1 and TS1/22, produce the same degree of inhibition as R6.5.D6, and anti-CD1 1b MAbs are without significant effect. (c) Unstimulated PMN adhere poorly to unstimulated HUVEC monolayers in vitro. MAbs reactive with 
CD18 (TS1/18) or ICAM-1 (R6.5.D6) significantly reduce this low level of adherence (7). In contrast to ELAM-1, there is a low level of constitutive expression of ICAM-1 on endothelial cells in vitro $(12,44)$.

Assuming that the inhibitory effect of the specific MAbs discussed above is the result of steric hindrance of receptor-ligand interactions, the overall weight of this evidence indicates that the unstimulated neutrophil uses a molecular mechanism for adhesion in common with lymphocytes, the receptor-ligand interaction of LFA-1 and ICAM-1 (17, 18, 45-47). The possibility that anti-LFA-1 antibodies are signaling in the neutrophil downregulation of as yet unidentified adhesive mechanisms seems unlikely in light of the results with CD18-deficient cells. The possibility that the anti-ICAM-1 MAb is signaling a reduction in other adherence mechanisms is discounted by the results using highly purified ICAM-1 in artificial membranes (17).

The results in this report further demonstrate that chemotactically stimulated PMN adhere to purified ICAM-1 in significantly greater numbers than unstimulated PMN. The mechanism of this increase remains unclear but one possibility is suggested by the results of experiments with normal cells pretreated with MAbs and experiments with CD18-deficient cells: chemotactic stimulation may enable Mac-1 to interact with ICAM-1. The failure of MAb R3.1 to completely inhibit the adhesion of AMLP stimulated PMN suggests the involvement of molecules other than LFA-1. Mac- 1 is implicated by the demonstration that anti-CD11b MAbs, OKM10 and LM2/1, reduced the level of adhesion of stimulated PMN to that of unstimulated PMN. The cooperative involvement of both heterodimers in neutrophil-ICAM-1 adhesion is shown by the additive inhibition of combinations of anti-CD11a and CD1 1b MAbs, essentially reducing adherence to the level induced by the anti-CD18 or anti-ICAM-1 MAbs (i.e., the level of adherence to the control protein, glycophorin). The involvement of ICAM-1 in this process is further supported by the finding that fMLP did not increase adherence of PMN to glycophorin. This latter observation discounts the possibility that stimulated PMN release factors that enhance the adhesivity of the artificial membrane in some manner independent of ICAM-1. The recruitment of Mac-1 in adhesion of PMN to ICAM- 1 is indicated by the failure of the anti-CD11b MAb LM2/1 to inhibit adhesion of unstimulated PMN. Whether this apparent recruitment is the result of newly upregulated molecules $(8,48-50)$, or altered function or distribution of existing molecules $(51-54)$ remains to be evaluated.

Chemotactic stimulation also leads to increased adhesion of PMN to unstimulated HUVEC monolayers (7), or monolayers stimulated in vitro for $18 \mathrm{~h}$ with IL-1, a condition that results in high expression of ICAM-1 and very low expression of ELAM-1 $(12,44)$. As in the experiments with purified ICAM-1, Mac-1 appears to play an important role in both experimental settings with HUVEC monolayers. In earlier studies an anti-CD11b MAb, $60.1(4,9)$, and an anti-ICAM-1 MAb, R56.5.D6 (7) markedly inhibited adherence of stimulated PMN to unstimulated HUVEC. In the current study we show that on 18-h IL-1 stimulated HUVEC, anti-CD11b MAbs are inhibitory, and in combination with an anti-CD1 la MAb (R3.1), reduce adherence to the same low level induced by the anti-ICAM-1 MAb, R6.5.D6 (7). Thus, the current evidence indicates that Mac-1 (CD11b/CD18) is recruited by chemotactic stimulation to interact with ICAM-1 on the sur- face of the endothelial cell since CD1 lb-dependent adhesion to HUVEC is blocked by the anti-ICAM-1 MAb. That Mac-1 may recognize ligands other than $\mathrm{iC} 3 \mathrm{~b}$ is supported by recent investigations from several laboratories $(8,54-58)$.

Within the first few minutes of contacting IL-1 stimulated endothelial monolayers, previously unstimulated normal PMN ruffle, assume a bipolar configuration, and migrate through the monolayer $(7,59)$. CD18-deficient PMN ruffle and become bipolar in shape, but fail to migrate through the monolayer (7). While CD18 and ICAM-1 are necessary for this migration (7), the specific heterodimers of the CD11/CD18 family have not been previously defined. The results in this report indicate that both Mac-1 and LFA-1 are involved, since MAbs reactive with LFA- 1 produce partial inhibition, and combinations of anti-CD1 la and anti-CD11b MAbs are as inhibitory as the anti-CD18 MAb, TS1/18.

The failure of anti-CD11b MAbs to inhibit transendothelial migration when used alone is intriguing. The ruffling and shape change of the PMN upon encountering the stimulated endothelium are consistent with cells exposed to a chemotactic factor $(6,60)$, an interpretation supported by the finding of chemotactic activity in conditioned media from cultures of endothelial cells (61-63). That chemotactic stimulation recruits the involvement of Mac-1 in adherence to endothelial cells may account for the observation that anti-CD11b MAbs potentiate the inhibition of transendothelial migration caused by anti-CD11a MAbs. If the interaction of LFA- 1 with ICAM-1 is sufficient for transendothelial migration to occur, then blocking Mac-1 would have little effect. However, when LFA-1 is blocked by anti-CD1 la MAbs, adhesion and migration may be promoted by Mac-1 as a result of local chemotactic stimulation, thus accounting for the additive effects of the anti-CD11b MAbs. The following considerations may be important as well: Mac-1 appears to be necessary for migration of PMN over a surface (8), though its role can be minor when $\mathrm{PMN}$ are migrating through a three-dimensional matrix (64). If adhesion-independent mechanisms are predominantly used by $\mathrm{PMN}$ for transendothelial migration following attachment to cytokine-stimulated, confluent monolayers of HUVEC, the ability of anti-CD11/CD18 and anti-ICAM-1 MAbs to inhibit migration would be limited to their ability to block the attachment of PMN to the monolayer. It is important to note that these MAbs, as shown in this and previous reports (8), do not inhibit at the level of chemotactic activation of bipolar shape change, a necessary step in the locomotion of PMN (60); and that the anti-CD1 la MAbs neither inhibit nor promote Mac-1-dependent functions such as adhesion to proteincoated glass and homotypic aggregation (8).

The factors that account for attachment and emigration of PMN through endothelium appear to be complex. It is now clear that cytokine-stimulated endothelial cells play an active role through increased expression of ELAM-1, ICAM-1 and probably additional adhesive factors. They also appear to produce a chemotactic stimulus that could modulate the adhesive molecules on the neutrophil by recruiting the involvement of Mac-1 in the cell's attachment to ICAM-1.

\section{Acknowledgments}

This study was supported in part by National Institutes of Health grants AI-23521, AI-19031, RR-05425-25, and HL-41408. 


\section{References}

1. Gimbrone, Jr., M. A., A. F. Brock, and A. I. Schafer. 1984. Leukotriene $B_{4}$ stimulates polymorphonuclear leukocyte adhesion to cultured vascular endothelial cells. J. Clin. Invest. 74:1552-1555.

2. Tonnesen, M. G., L. A. Smedley, and P. M. Henson. 1984. Neutrophil-endothelial cell interactions: Modulation of neutrophil adhesiveness induced by complement fragments $\mathrm{C5a}$ and $\mathrm{C5} \mathrm{a}_{\text {desArg }}$ and formyl-methionyl-leucyl-phenylalanine in vitro. J. Clin. Invest. 74:1581-1592.

3. Charo, I. F., C. Yuen, H. D. Perez, and I. M. Goldstein. 1986. Chemotactic peptides modulate adherence of human polymorphonuclear leukocytes to monolayers of cultured endothelial cells. J. Immunol. 136:3412-3419.

4. Pohlman, T. H., K. A. Stanness, P. G. Beatty, H. D. Ochs, and J. M. Harlan. 1986. An endothelial cell surface factor(s) induced in vitro by lipopolysaccharide, interleukin-1, and tumor necrosis factor increases neutrophil adherence by a CDw 18 (LFA)-dependent mechanism. J. Immunol. 136:4548-4553.

5. Gamble, J. R., J. M. Harlan, S. J. Klebanoff, and M. A. Vadas. 1985. Stimulation of the adherence of neutrophils to umbilical vein endothelium by human recombinant tumor necrosis factor. Proc. Natl. Acad. Sci. USA. 82:8667-8674.

6. Smith, C. W., J. C. Hollers, R. A. Patrick, and C. Hassett. 1979. Motility and adhesiveness in human neutrophils: Effects of chemotactic factors. J. Clin. Invest. 63:221-229.

7. Smith, C. W., R. Rothlein, B. J. Hughes, M. M. Mariscalco, F. C. Schmalstieg, H. E. Rudloff, and D. C. Anderson. 1988. Recognition of an endothelial determinant for CD18-dependent human neutrophil adherence and transendothelial migration. J. Clin. Invest. 82:17461756.

8. Anderson, D. C., L. J. Miller, F. C. Schmalstieg, R. Rothlein, and T. A. Springer. 1986. Contributions of the Mac-1 glycoprotein family to adherence-dependent granulocyte functions: Structure-function assessments employing subunit-specific monoclonal antibodies. J. Immunol. 137:15-27.

9. Zimmerman, G. A., and T. M. McIntyre. 1988. Neutrophil adherence to human endothelium in vitro occurs by CDw18 (Mol, MAC-1/LFA-1/GP150,95) glycoprotein-dependent and independent mechanisms. J. Clin. Invest. 81:531-537.

10. Pohlman, T. H., R. S. Munford, and J. M. Harlan. 1987. Deacylated lipopolysaccharide inhibits neutrophil adherence to endothelium induced by lipopolysaccharide in vitro. J. Exp. Med. 165:1393-1402.

11. Dunn, C. J., and W. E. Fleming. 1984. Increased adhesion of polymorphonuclear leukocytes to vascular endothelium by specific interaction of endogenous (interleukin-1) and exogenous (lipopolysaccharide) substances with endothelial cells "in vitro." Eur. J. Rheum. Inflam. 7:80-86.

12. Pober, J. S., M. A. Gimbrone, L. A. Lapierre, D. L. Mendrick, W. Fiers, R. Rothlein, and T. A. Springer. 1986. Overlapping patterns of antigenic modulation by interleukin 1, tumor necrosis factor and immune interferron. J. Immunol. 137:1893-1896.

13. Pober, J. S., L. A. Lapierre, A. H. Stolpen, T. A. Brock, T. A. Springer, W. Fiers, M. P. Bevilacqua, D. L. Mendrick, and M. A. Gimbrone, Jr. 1987. Activation of cultured human endothelial cells by recombinant lymphotoxin: comparison with tumor necrosis factor and interleukin 1 species. J. Immunol. 138:3319-3324.

14. Broudy, V. C., J. M. Harlan, and J. W. Adamson. 1987. Disparate effects of tumor necrosis factor-a/cachectin and tumor necrosis factor-b/lymphotoxin on hematopoietic growth factor production and neutrophil adhesion molecule expression by cultured human endothelial cells. J. Immunol. 138:4298-4302.

15. Rothlein, R., M. L. Dustin, S. D. Marlin, and T. A. Springer. 1986. An intercellular adhesion molecule (ICAM-1) distinct from LFA-1. J. Immunol. 137:1270-1275.

16. Dustin, M. L., R. Rothlein, A. K. Bhan, C. A. Dinarello, and T. A. Springer. 1986. Induction by IL-1 and interferon-gamma: tissue distribution, biochemistry, and function of a natural adherence molecule (ICAM-1). J. Immunol. 137:245-254.

17. Marlin, S. D., and T. A. Springer. 1987. Purified intercellular adhesion molecule-1 (ICAM-1) is a ligand for lymphocyte functionassociated antigen 1 (LFA-1). Cell. 51:813-819.

18. Makgoba, M. W., M. E. Sanders, G. E. Ginther Luce, M. L. Dustin, T. A. Springer, E. A. Clark, P. Mannoni, and S. Shaw. 1988. ICAM-1 a ligand for LFA-1-dependent adhesion of $\mathrm{B}, \mathrm{T}$ and myeloid cells. Nature (Lond.). 331:86-88.

19. Anderson, D. C., F. C. Schmalstieg, M. J. Finegold, B. J. Hughes, R. Rothlein, L. J. Miller, S. Kohl, M. F. Tosi, R. L. Jacobs, T. C. Waldrop, A. S. Goldman, W. T. Shearer, and T. A. Springer. 1985. The severe and moderate phenotypes of heritable Mac-1, LFA-1, p150,95 deficiency: their quantitative definition and relation to leukocyte dysfunction and clinical features. J. Infect. Dis. 152:668-689.

20. Anderson, D. C., M. L. Mace, R. R. Martin, and C. W. Smith. 1981. Recurrent infection in glycogenosis type 1b: Abnormal neutrophil motility related to impaired redistribution of adhesion sites. $J$. Infect. Dis. 143:447-459.

21. Sanchez-Madrid, F., J. Nagy, E. Robbins, P. Simon, and T. A. Springer. 1983. A human leukocyte differentiation antigen family with distinct alpha subunits and a common beta subunit: The lymphocyte function associated antigen (LFA-1), the C3bi complement receptor (OKM1/Mac-1), and the p150,95 molecule. J. Exp. Med. 158:17851803.

22. Miller, L. J., D. F. Bainton, N. Borregaard, and T. A. Springer. 1987. Stimulated mobilization of monocyte Mac-1 and p150,95 adhesion proteins from an intracellular vesicular compartment to the cell surface. J. Clin. Invest. 80:535-544.

23. Miller, L. J., R. Schwarting, and T. A. Springer. 1986. Regulated expression of the Mac-1, LFA-1, p150,95 glycoprotein family during leukocyte differentiation. J. Immunol. 137:2891-2900.

24. Todd, III, R. F., A. VanAgthoven, S. F. Schlossman, and C. Terhorst. 1982. Structural analysis of differentiation antigens Mol and Mo2 on human monocytes. Hybridoma. 1:329.

25. Springer, T. A., G. Galfre, D. S. Secher, and C. Milstein. 1979. Mac-1: A macrophage differentiation antigen identified by a monoclonal antibody. Eur. J. Immunol. 9:301-306.

26. Dana, N., B. Styrt, J. D. Griffin III, R. F. Todd, M. S. Klempner, and M. A. Arnaout. 1986. Two functional domains in the phagocyte membrane glycoproteins Mol identified with monoclonal antibodies. J. Immunol. 137:3259-3263.

27. Barstable, C. J., W. F. Boomer, G. Brown, G. Galfre, C. Milstein, A. F. Williams, and A. Ziegler. 1978. Production of monoclonal antibodies to group A erythrocytes, HLA and other human cell surface antigens. New tools for genetic analysis. Cell. 14:9-19.

28. Buchanan, M. R., C. A. Crowley, R. E. Rosin, Jr., M. A. Gimbrone, and B. M. Babior. 1982. Studies on the interaction between GP-180 deficient neutrophils and vascular endothelium. Blood. 60:160-165.

29. Jaffe, E. A., R. L. Nachman, C. G. Becker, and C. R. Minick. 1973. Culture of human endothelial cells from umbilical veins. Identification by morphologic and immunologic criteria. J. Clin. Invest. 52:2745-2757.

30. Gimbrone, M. A. 1975. Culture of vascular endothelium. Prog. Hemostasis Thromb. 3:1-28.

31. Voyta, J. C., D. P. Via, C. E. Butlerfield, and B. R. Zetter. 1984. Identification and isolation of endothelial cells based on their increased uptake of acetylated low density lipoprotein. J. Cell Biol. 99:2034-2040.

32. Smith, C. W., and J. C. Hollers. 1980. Motility and adhesiveness in human neutrophils. Redistribution of chemotactic factor induced adhesion sites. J. Clin. Invest. 65:804-812.

33. Anderson, D. C., G. S. Krishna, B. J. Hughes, M. L. Mace, C. W. Smith, and B. L. Nichols. 1983. Impaired polymorphonuclear leukocyte motility in malnourished infants: relationship to functional abnormalities of cell adherence. J. Lab. Clin. Med. 101:881-895.

34. Anderson, D. C., B. J. Hughes, and C. W. Smith. 1981. Abnor- 
mal mobility of neonatal polymorphonuclear leukocytes. Relationship to impaired redistribution of surface adhesion sites by chemotactic factor or colchicine. J. Clin. Invest. 68:863-874.

35. Forrester, J. V., and J. M. Lackie. 1984. Adhesion of neutrophil leukocytes under conditions of flow. J. Cell. Sci. 70:93-110.

36. Lawrence, M. B., L. V. McIntire, and S. G. Eskin. 1987. Effect of flow on polymorphonuclear leukocyte/endothelial cell adhesion. Blood. 70:1284-1290.

37. Harlan, J. M., P. D. Killen, F. M. Senecal, B. R. Schwartz, E. K Yee, R. F. Taylor, P. G. Beatty, T. H. Price, and H. D. Ochs. 1985. The role of neutrophil membrane glycoprotein GP-150 in neutrophil adherence to endothelium in vitro. Blood. 66:167-178.

38. Arnaout, M. A., E. A. Wang, S. C. Clark, and C. A. Sieff. 1986. Human recombinant granulocyte-macrophage colony-stimulating factor increases cell-to-cell adhesion and surface expression of adhesion-promoting surface glycoproteins on mature granulocytes. J. Clin. Invest. 78:597-601.

39. McFall, T. L., G. A. Zimmerman, N. H. Augustine, and H. R. Hill. 1987. Effect of group b streptococcal type-specific antigen on polymorphonuclear leukocyte function and polymorphonuclear leukocyte-endothelial cell interaction. Pediatr. Res. 21:517-523.

40. Beesley, J. E., J. D. Pearson, A. Hutchings, J. S. Carleton, and J. L. Gordon. 1979. Granulocyte migration through endothelium in culture. J. Cell. Sci. 38:237-248.

41. Hoover, R. L., M. Robinson, and M. J. Karnovsky. 1987. Adhesion of polymorphonuclear leukocytes to endothelium enhances the efficiency of detoxification of oxygen-free radicals. Am. J. Pathol. 126:258-268.

42. Marlin, S. D., C. C. Morton, D. C. Anderson, and T. A. Springer. 1986. LFA-1 immunodeficiency disease. Definition of the genetic defect and chromosomal mapping of alpha and beta subunits by complementation in hybrid cells. J. Exp. Med. 164:855-867.

43. Wallis, W. J., P. G. Beatty, H. D. Ochs, and J. M. Harlan. 1985. Human monocyte adherence to cultured vascular endothelium: monoclonal antibody-defined mechanisms. J. Immunol. 135(4): 2323-2330.

44. Bevilacqua, M. P., J. S. Pober, D. L. Mendrick, R. S. Cotran, and M. A. Gimbrone, Jr. 1987. Identification of an inducible endothelial-leukocyte adhesion molecule. Proc. Natl. Acad. Sci. USA. 84:9238-9242.

45. Dougherty, G. J., S. Murdoch, and N. Hogg. 1988. The function of human intercellular adhesion molecule-1(ICAM-1) in the generation of an immune response. Eur. J. Immunol. 18:35-39.

46. Boyd, A. W., S. O. Wawryk, G. F. Burns, and J. V. Fecondo. 1988. Intercellular adhesion molecule 1 (ICAM-1) has a central role in cell-cell contact-mediated immune mechanisms. Proc. Natl. Acad. Sci. USA. 85:3095-3099.

47. Bierer, B. E., and S. J. Burakoff. 1988. T cell adhesion molecules. FASEB (Fed. Am. Soc. Exp. Biol.) J. 2:2584-2590.

48. Anderson, D. C., F. C. Schmalstieg, S. Kohl, M. A. Arnaout, B. J. Hughes, M. F. Tosi, G. J. Buffone, B. R. Brinkley, W. D. Dickey, J. S. Abramson, T. A. Springer, L. A. Boxer, J. M. Hollers, and C. W. Smith. 1984. Abnormalities of polymorphonuclear leukocyte function associated with a heritable deficiency of high molecular weight surface glycoproteins (GP138). Common relationship to diminished cell adherence. J. Clin. Invest. 74:536-551.

49. O'Shea, J. J., E. J. Brown, B. E. Seligmann, J. A. Metcalf, M. M. Frank, and J. I. Gallin. 1985. Evidence for distinct intracellular pools of receptors for $\mathrm{C} 3 \mathrm{~b}$ and $\mathrm{C} 3 \mathrm{bi}$ in human neutrophils. J. Immunol. 134:2580-2587.

50. Petty, H. R., J. W. Francis, III, R. F. Todd, P. R. Petrequin, and L. A. Boxer. 1987. Neutrophil C3bi receptors: formation of membrane clusters during cell triggering requires intracellular granules. J. Cell. Physiol. 133:235-242.

51. Vedder, N. B., and J. M. Harlan. 1988. Increased surface expression of $\mathrm{CD} 11 \mathrm{~b} / \mathrm{CD} 18$ (Mac-1) is not required for stimulated neutrophil adherence to cultured endothelium. J. Clin. Invest. 81:676682.

52. Philips, M., J. Buyon, R. Winchester, G. Weissmann, and S. Abramson. 1988. Upregulation of $\mathrm{iC} 3 \mathrm{~b}$ receptors (CR3) is neither necessary nor sufficient to promote neutrophil aggregation. J. Clin. Invest. 82:495-501.

53. Detmers, P. A., S. D. Wright, E. Olsen, B. Kimball, and Z. A. Cohn. 1987. Aggregation of complement receptors on human neutrophils in the absence of ligand. J. Cell Biol. 105:1137-1145.

54. Altieri, D. C., and T. S. Edgington. 1988. The saturable high affinity association of Factor X to ADP-stimulated monocytes defines a novel function of the Mac-1 receptor. J. Biol. Chem. 263:7007-7015.

55. Wright, S. D., and M. T. C. Jong. 1986. Adhesion-promoting receptors on human macrophages recognize escherichia coli by binding to lipopolysaccharide. J. Exp. Med. 164:1876-1888.

56. Ross, G. D., R. A. Thompson, M. J. Walport, T. A. Springer, J. V. Watson, R. H. R. Ward, J. Lida, S. L. Newman, R. A. Harrison, and P. J. Lachmann. 1985. Characterization of patients with an increased susceptibility to bacterial infections and a genetic deficiency of leukocyte membrane complement receptor type 3 and the related membrane antigen LFA-1. Blood. 66:882-890.

57. Wright, S. D., M. T. C. Jong, and S. M. Levin. 1988. CR3 expresses two binding sites, one for RGD-peptide, and one for bacterial LPS. FASEB (Fed. Am. Soc. Exp. Biol.) J. 2:1237a. (Abstr.)

58. Lo, S. K., and S. D. Wright. 1988. CR3 mediates binding or PMN to endothelial cells (EC) via its RGD binding, not the LPS binding site. FASEB (Fed. Am. Soc. Exp. Biol.) J. 2:1236a. (Abstr.)

59. Furie, M. B., and D. D. McHugh. 1987. Stimulation of neutrophil transendothelial migration by interleukin-1. J. Cell Biol. 105:276a.(Abstr.)

60. Zigmond, S. H., H. I. Levitsky, and B. J. Kreel. 1981. Cell polarity: an examination of its behavioral expression and its consequences for polymorphonuclear leukocyte chemotaxis. J. Cell Biol. 89:585-592.

61. O'Brien, R. F., M. P. Seton, J. S. Makarski, D. M. Center, and S. Rounds. 1984. Thiourea causes endothelial cells in tissue culture to produce neutrophil chemoattractant activity. Am. Rev. Respir. Dis. 130:103-109.

62. Mercandetti, A. J., T. A. Lane, and M. E. M. Colmerauer. 1984. Cultured human endothelial cells elaborate neutrophil chemoattractants. J. Lab. Clin. Med. 104:370-377.

63. Gudewicz, P. W., L. E. Odekon, P. J. DelVecchio, and T. M. Saba. 1988. Generation of neutrophil chemotactic activity by phorbol ester-stimulated calf pulmonary artery endothelial cells. J. Leuk. Biol. 440:1-7.

64. Schmalstieg, F. C., H. E. Rudloff, G. R. Hillman, and D. C. Anderson. 1986. Two dimensional and three dimensional movement of human polymorphonuclear leukocytes: Two fundamentally different mechanisms of location. J. Leuk. Biol. 40:677-708. 